\title{
Solar cycle variations of stratospheric ozone and temperature in simulations of a coupled chemistry-climate model
}

\author{
J. Austin ${ }^{1}$, L. L. Hood ${ }^{2}$, and B. E. Soukharev ${ }^{2}$ \\ ${ }^{1}$ NOAA Geophysical Fluid dynamics Laboratory, PO Box 308, Princeton, NJ 08542-0308, USA \\ ${ }^{2}$ Lunar and Planetary Laboratory, University of Arizona, Tucson, AZ 85721, USA
}

Received: 30 October 2006 - Published in Atmos. Chem. Phys. Discuss.: 27 November 2006

Revised: 31 January 2007 - Accepted: 21 March 2007 - Published: 28 March 2007

\begin{abstract}
The results from three 45-year simulations of a coupled chemistry climate model are analysed for solar cycle influences on ozone and temperature. The simulations include UV forcing at the top of the atmosphere, which includes a generic 27-day solar rotation effect as well as the observed monthly values of the solar fluxes. The results are analysed for the 27-day and 11-year cycles in temperature and ozone. In accordance with previous results, the 27-day cycle results are in good qualitative agreement with observations, particularly for ozone. However, the results show significant variations, typically a factor of two or more in sensitivity to solar flux, depending on the solar cycle.

In the lower and middle stratosphere we show good agreement also between the modelled and observed 11-year cycle results for the ozone vertical profile averaged over low latitudes. In particular, the minimum in solar response near $20 \mathrm{hPa}$ is well simulated. In comparison, experiments of the model with fixed solar phase (solar maximum/solar mean) and climatological sea surface temperatures lead to a poorer simulation of the solar response in the ozone vertical profile, indicating the need for variable phase simulations in solar sensitivity experiments. The role of sea surface temperatures and tropical upwelling in simulating the ozone minimum response are also discussed.
\end{abstract}

\section{Introduction}

Variations in the solar output have long been thought to influence climate (e.g. Hershel, 1801) but rigorous links to the troposphere have only relatively recently been established (e.g. Baldwin and Dunkerton, 1989; Coughlin and Tung, 2004). While the energy output of the sun (total solar irradiance, TSI) clearly has a significant impact on the mean climate

Correspondence to: J. Austin

(john.austin@noaa.gov) on energetic grounds, variations in TSI are too small to lead to a large signal in tropospheric processes by direct radiative forcing alone. Solar variability is strongly dependent on wavelength so that even though TSI variability is a fraction of a \% (e.g. Frölich, 2000), the variability increases substantially at the shorter wavelengths which affect ozone production and loss. A plausible mechanism for solar influences on the atmosphere, therefore, might invoke changes in stratospheric temperature and ozone due to ultraviolet (UV) variations. Such mechanisms have been used by Haigh (1994) for example to demonstrate the possible existence of a solar impact on the troposphere using model simulations.

Solar cycle variations in both ozone and temperature are now well established in the stratosphere from observations (e.g. Hood and McCormack, 1992) and from model simulations (e.g. Brasseur, 1993). The most well-known solar variation is probably the 11-year Schwabe cycle, which has been observed in the sunspot record for over a century (Schwabe, 1843). Solar variations also occur on much shorter timescales, particularly in the range 13-80 days due to harmonics and subharmonics of the 27-day solar rotation period (e.g. Zhou et al., 1997; Hood and Zhou, 1998).

To observe small changes associated with the solar cycle requires a high density of data points in space and time. Away from the Earth's surface, satellite data provide the best opportunity of detecting such signals, but only two complete 11-year solar cycles are available from this source. Many more cycles exist for the solar rotation periods. These have now been analysed in detail and reliable information exists on both temperature and ozone (Hood, 1986; Hood and Cantrell, 1988; Chandra et al., 1994; Chen et al., 1997).

Modelling studies have shown good agreement with observations for the 27-day cycle (Brasseur, 1993; Fleming et al., 1995; Williams et al., 2001), which has similar spectral changes in UV flux than the Schwabe cycle. For the 11-year cycle, even though ozone column amounts are correctly simulated (e.g. Zerefos et al., 1997), models have been consistent

Published by Copernicus GmbH on behalf of the European Geosciences Union. 
Table 1. List of model experiments with AMTRAC, simulating the past. For each simulation, the date indicated refers to the corresponding amounts for all the external forcings, including the WMGHGs and halogen amounts.

\begin{tabular}{llll}
\hline Name & Dates & Solar Forcing & Description \\
\hline TRANSA & $1960-2005$ & Transient & Transient forcings, A \\
TRANSB & $1960-2005$ & Transient & Transient forcings, B \\
TRANSC & $1960-2005$ & Transient & Transient forcings, C \\
\hline SL2000 & 2000 & Fixed mid-cycle & Control run, 31 years \\
& $F_{10.7}=147$ & & \\
SL2000B & 2000 & Fixed solar max. & Control run, 26 years \\
& $F_{10.7}=222$ & & \\
\hline
\end{tabular}

in simulating too much ozone in the middle stratosphere, and not enough in the lower and upper stratosphere (Brasseur, 1993; Haigh, 1994; Shindell et al. 1999; Tourpali et al., 2003; Egorova et al., 2004). Despite improvements in models, including the use of 3-D coupled chemistry-climate models (e.g. Labitzke et al., 2002) these differences persist. A recent synthesis of observations and comparison with model results is given by Soukharev and Hood (2006). To date, the simulations have typically been run in solar maximum versus solar minimum mode, which is of course not how the atmosphere behaves. This is to minimise the computational expense of multi-decadal simulations with 3-D models. Therefore, there is a possibility either that the full solar cycle needs to be represented, or that there are missing processes in many of the simulations completed. Early work (Callis et al., 2001, and references therein) have suggested that $\mathrm{NO}_{\mathrm{x}}$ generation in the upper mesosphere due to energetic electron precipitation (EEP) may be one such missing process and recent works (Langematz, et al., 2005; Rozanov et al., 2005a) have addressed this using updated models. These events are expected to occur more during solar minimum and in the model simulations the extra $\mathrm{NO}_{\mathrm{x}}$ is advected to the middle stratosphere where ozone can be depleted. As a consequence of the ozone "self healing" effect additional ozone is generated in the lower stratosphere. Thus, the ozone total column could be relatively unaffected by this process but the vertical profile of the ozone change would be improved in comparison with measurements. However, the amount of $\mathrm{NO}_{\mathrm{x}}$ inserted into the mesosphere in some model studies appears to be more than can be expected by EEP events alone, and questions remain as to how sufficient $\mathrm{NO}_{\mathrm{x}}$ can be advected to the tropical middle stratosphere. Indeed, recent estimates (Hood and Soukharev, 2006) tend not to support the presence of a significant impact of solar cycle $\mathrm{NO}_{\mathrm{x}}$ on tropical ozone. In this work, 27-day and 11-year solar cycle variations of ozone and temperature are investigated using transient simulations of a coupled chemistry-climate model with observed forcings.

\section{Model simulations}

Results are presented from simulations of the coupled chemistry climate model AMTRAC (Atmospheric Model with TRansport And Chemistry). The simulations have been described and results have been presented previously for ozone, water and age of air (Austin and Wilson, 2006; Austin et al., 2007), and contributed to the model intercomparison experiment REF1 of Eyring et al. (2006). The model includes comprehensive stratospheric chemistry but simplified tropospheric chemistry, including mainly methane chemistry. The concentrations of well mixed greenhouse gases (WMGGs) and organic halogen molecules have been specified from observations for the period 1960-2005, and provide radiative forcings to the model climate. Sea Surface Temperatures and Sea Ice (collectively referred to as SSTs) are specified at the model lower boundary as a function of time from the Hurrell dataset (Hurrell et al., personal communication, 2005). Observed aerosol extinctions are included to represent the impact of volcanic eruptions. Monthly averaged solar forcing is specified from observations and a 27-day variation in solar forcing is superimposed as a sine wave. The model does not simulate a quasi-biennial oscillation (QBO), nor is one forced externally. Twelve complete solar cycles of model results are available from the three ensemble runs, together with 26 years or more each of fixed phase solar maximum/solar mean timeslice experiments. See Table 1 for the list of experiments completed.

Solar cycles are included in the model in both the radiation and the photochemistry, but in different ways. In the radiation, the spectrally varying solar flux changes monthly in accordance with the calculations of Lean et al. (2005) but the 27-day solar rotation period was not included, because the large changes in the radiation code could not be included on a timely basis. The radiation scheme consists of 18 short wave bands, as described in more detail in Anderson et al. (2004) and references therein. In the photochemistry, solar variability is included by a linear parameterisation of the $10.7 \mathrm{~cm}$ flux, including a monthly mean term and a term representing the 27-day solar rotation period.

The photolysis rates are calculated using a lookup table for solar maximum and solar minimum conditions. For each of the two solar phases, the 27-day amplitude was calculated using Upper Atmosphere Research Satellite SOLar STellar Irradiance Comparison Experiment (UARS SOLSTICE) data (Rottman et al., 1993; Rottman, 1999), thus requiring four data points for each photolysis coefficient, and for each of the independent parameters of the lookup table (pressure, column ozone, solar zenith angle). Computation of the lookup table required solar flux data for the 158 bands of the photolysis rate code for periods close to solar maximum and solar minimum. The corresponding $10.7 \mathrm{~cm}$ flux values were then used in the parameterisation (below). Model sensitivity to the 11-year solar cycle is later analysed in terms of the $10.7 \mathrm{~cm}$ flux, and the 27-day oscillation is analysed for solar 
maximum only in terms of the $205 \mathrm{~nm}$ flux implied in the SOLSTICE data.

Each photolysis rate is given by

$J=c\left(J_{10.7}+J_{27} \sin \phi\right)$

Where $\mathrm{c}$ is a factor to correct for seasonal changes in the sunearth distance and $\phi$ is the phase of the 27-day oscillation, assumed to be a sine wave with largest amplitude at solar maximum in accordance with observations. $J_{10.7}$ and $J_{27}$ are the photolysis rate and increment respectively for the $10.7 \mathrm{~cm}$ flux and the 27-day oscillation, which are determined by

$J_{10.7}=J_{\min }+\left(F_{10.7}-69.6\right)\left(J_{\max }-J_{\min }\right) / 154.3$

$J_{27}=J_{27 \min }+\left(F_{10.7}-69.6\right)\left(J_{27 \max }-J_{27 \min }\right) / 154.3$

$J_{\max }$ and $J_{\min }$ are the photolysis rates for solar maximum and solar minimum respectively. $F_{10.7}$ is the $10.7 \mathrm{~cm}$ solar flux corresponding to the model time, which is linearly interpolated between consecutive monthly mean observed values. $J_{27 \text { max }}$ and $J_{27}$ min are the photolysis rate increment for the 27-day oscillation. The quantities 69.6 and 154.3 in the above equations refer to the $10.7 \mathrm{~cm}$ flux value at solar minimum, and the amplitude of the solar cycle appropriate to the photolysis rate computations. As indicated by e.g. Rottman (1999) the amplitude of the 27-day oscillation varies substantially over the course of the 11-year Schwabe cycle and such a variation is incorporated into Eq. (3). We do not explore the physics of this, but point out that the oscillation arises from movements of sunspots around the rotating sun which peak during the maximum of the Schwabe cycle, when higher numbers of sunspots are present. The $10.7 \mathrm{~cm}$ radio flux is a useful proxy as detailed measurements exist for over 5 solar cycles. In this work, we investigate the 27-day cycle only at the times of the maxima in the Schwabe cycle. Figure 1 shows the observations of $10.7 \mathrm{~cm}$ flux $\left(F_{10.7}\right)$ since 1950 at monthly resolution and for comparison a sinusoidal function with 11-year period, mean 145 and amplitude 75 units is drawn in the figure. While the sinusoidal function fits the general behaviour of the flux values, some cycles are much stronger than others, and in general, the flux is slightly squarer in shape than the sinusoid. No additional solar impacts such as EEP effects are included in the model.

In addition to the above experiments, a 31-year control run (SL2000) was completed with fixed seasonally varying SSTs and fixed WMGGs, no volcanic aerosol and a fixed mid-cycle solar forcing. An additional 26 year simulation (SL2000B) was also completed for the year 2000 identical to the control but with the $10.7 \mathrm{~cm}$ flux increased by 75 units, corresponding to the flux in January 2002. To reduce the model spinup required, Experiment SL2000B was initialised with the results five years after the start of Experiment SL2000. Therefore, results for Experiments SL2000 and SL2000B are compared for only 26 years. For comparison with the transient runs, results for the difference SL2000B-SL2000 are rescaled to 100 units of $F_{10.7}$.

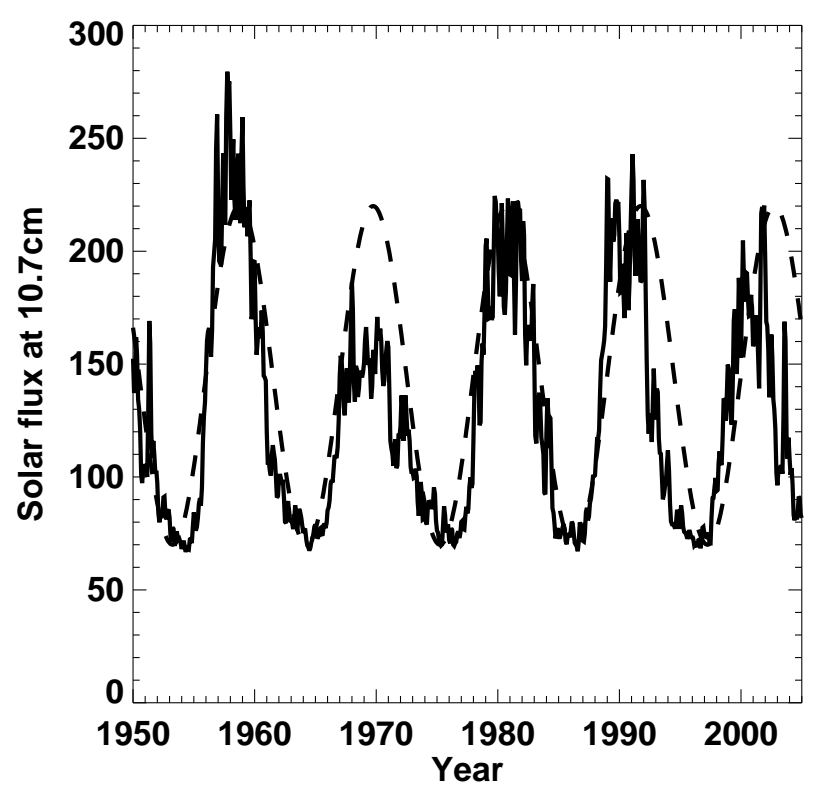

Fig. 1. Observed monthly mean solar flux at $10.7 \mathrm{~cm}$ wavelength (solid line). The broken line shows an approximate sinusoidal fit through the data with an 11-year period. The data were obtained from the NOAA Geophysical Data Center (http://www.ngdc.noaa. gov/stp/SOLAR/ftpsolarradio.html).

\section{Analysis of model data}

In analysing of the model results, we use the linear regression algorithms of the National Algorithm Group (NAG, 1999), implemented on the GFDL high performance computing system. For the 27-day oscillation, the regression equation assumed was

$\mathrm{O}_{3}=a_{0}+a_{1} t+a_{2} \sigma+a_{3} F_{10.7}+a_{4} \sin (\phi-\lambda)+\epsilon(t)$

where $t$ is time in days, $\sigma$ is the aerosol surface area estimated from the optical depth and $\lambda$ is an assumed phase lag. $\epsilon$ is the residual term. Model results from one year periods were used. To minimise seasonal effects, the ozone values in Eq. (4) were treated as a time series of 13.5 27-day periods, which were averaged to give a single 27-day sequence of values. Calculations were performed for the 61 values of the phase lag -30 to +30 days. This method was applied to the model results for one calendar year corresponding to the peaks in each of the four Schwabe cycles - 1970, 1981, 1991 and 2001, for each of the three ensemble members.

For the Schwabe cycle, a similar regression equation was assumed, where the ozone values were regressed separately for each month and for the annual average.

$\mathrm{O}_{3}=b_{0}+b_{1} t+b_{2} \sigma+b_{3} F_{10.7}+\epsilon(t)$

where $\mathrm{O}_{3}$ is the monthly averaged ozone amount from the model and $t$ is now in months. Equation (5) was applied for 

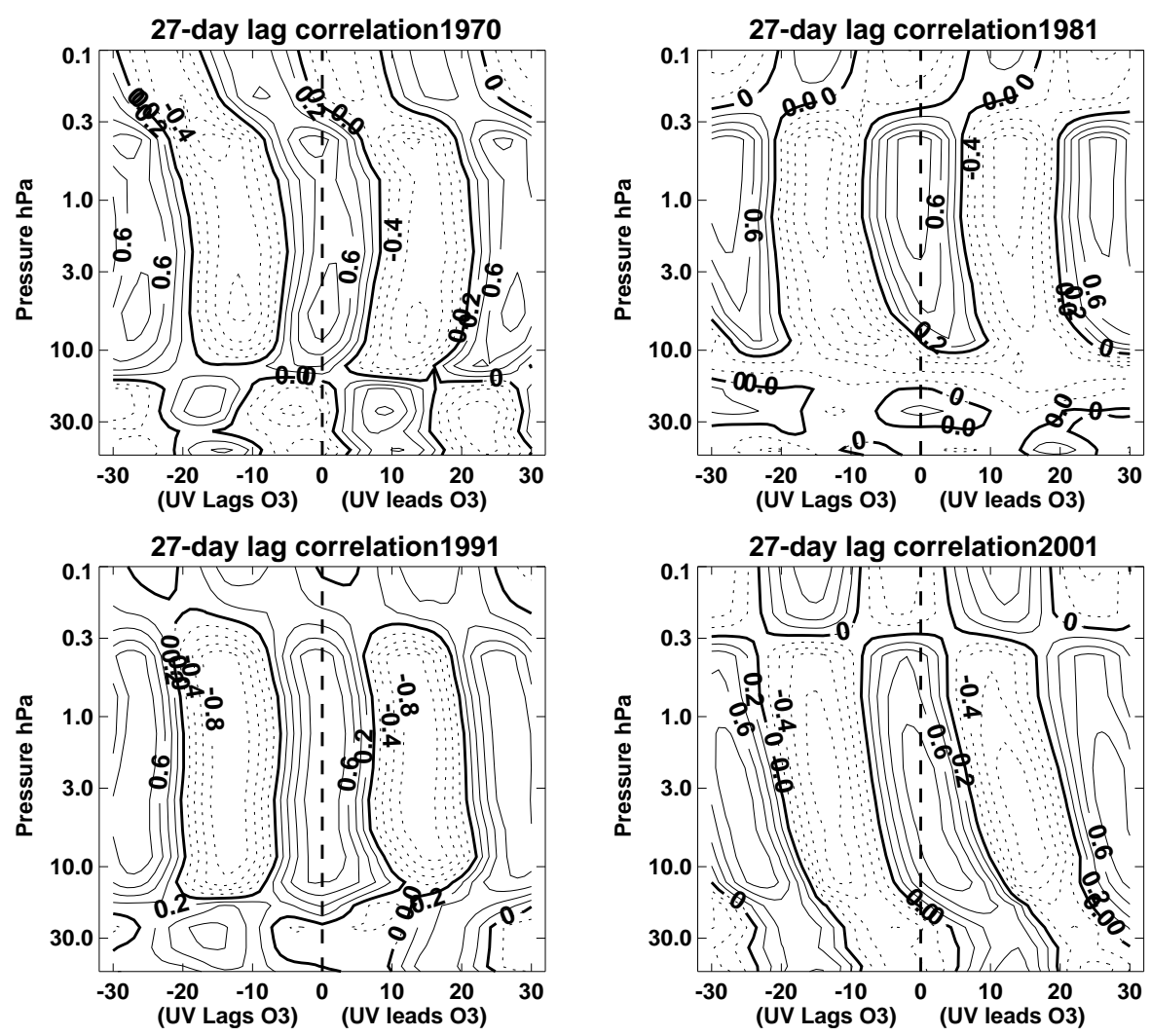

Fig. 2. Lag correlations between ozone and UV averaged over the latitude range $30^{\circ} \mathrm{S}$ to $30^{\circ} \mathrm{N}$ for the 27 day oscillation for the years indicated for the four solar cycles. The contour interval is 0.2 .

the full 45 year model simulation period, using monthly average values for each of the three ensemble members. The regression model is similar to that of Soukharev and Hood (2006), but the main difference is that here we use $10.7 \mathrm{~cm}$ flux as the independent solar forcing term, as the model itself was driven by these flux values (Eqs. 1-3). Also, as the model does not have a tropical oscillation, the QBO term of Soukharev and Hood (2006) is not included.

Finally, the analysis was repeated using the simulated temperature as the dependent variable in the regression analysis.

\section{Results}

\subsection{The 27-day oscillation}

Results are presented of the sensitivity coefficient $a_{4} / \mathrm{O}_{3}$ for a one percent change in solar flux at $205 \mathrm{~nm}$ wavelength. Results are also presented for the correlation coefficient between $\mathrm{O}_{3}$ and $\sin \phi$, i.e. the correlation between $\mathrm{O}_{3}$ and the 27-day oscillation. We repeat the presentation of Williams et al. (2001) with the AMTRAC results and a somewhat more extensive result database. Williams et al. used an early version of the Unified Model with Eulerian TRansport and Chemistry (UMETRAC) (Austin et al., 2000). Since that time, the chemistry has undergone several iterations before reaching the current version (AMTRAC) which was developed for the GFDL climate model AM2 (Anderson et al., 2004).

Figure 2 shows the 27-day lag correlation for ozone for the four cycles, averaged for the region $30^{\circ} \mathrm{S}$ to $30^{\circ} \mathrm{N}$. The results are similar to those presented by Williams et al., Fig. 2. Williams et al. noted that significant differences occurred when the UV change was applied to both radiation and photochemistry, as opposed to just the photochemistry as applied here. However, we also find substantial variations between one solar cycle and the next. For example the lag at the correlation peak increases downwards between 1 and $10 \mathrm{hPa}$ for the year 1981 and 2001 but does not change substantially for 1970 and 1991.

The results for 2001 are in good agreement with Zhou et al. (1997), their Fig. 7, which covers the period October 1991-September 1994. However in our results, the region of high correlation extends above the stratopause. Zhou et al. note that the correlation between ozone and UV changes during the period. This is explored further in Hood and Zhou (1998) who separate the results into two 500 day periods. The first half of the period yields a lag correlation more similar to our results for 1991 while the second half yields results 

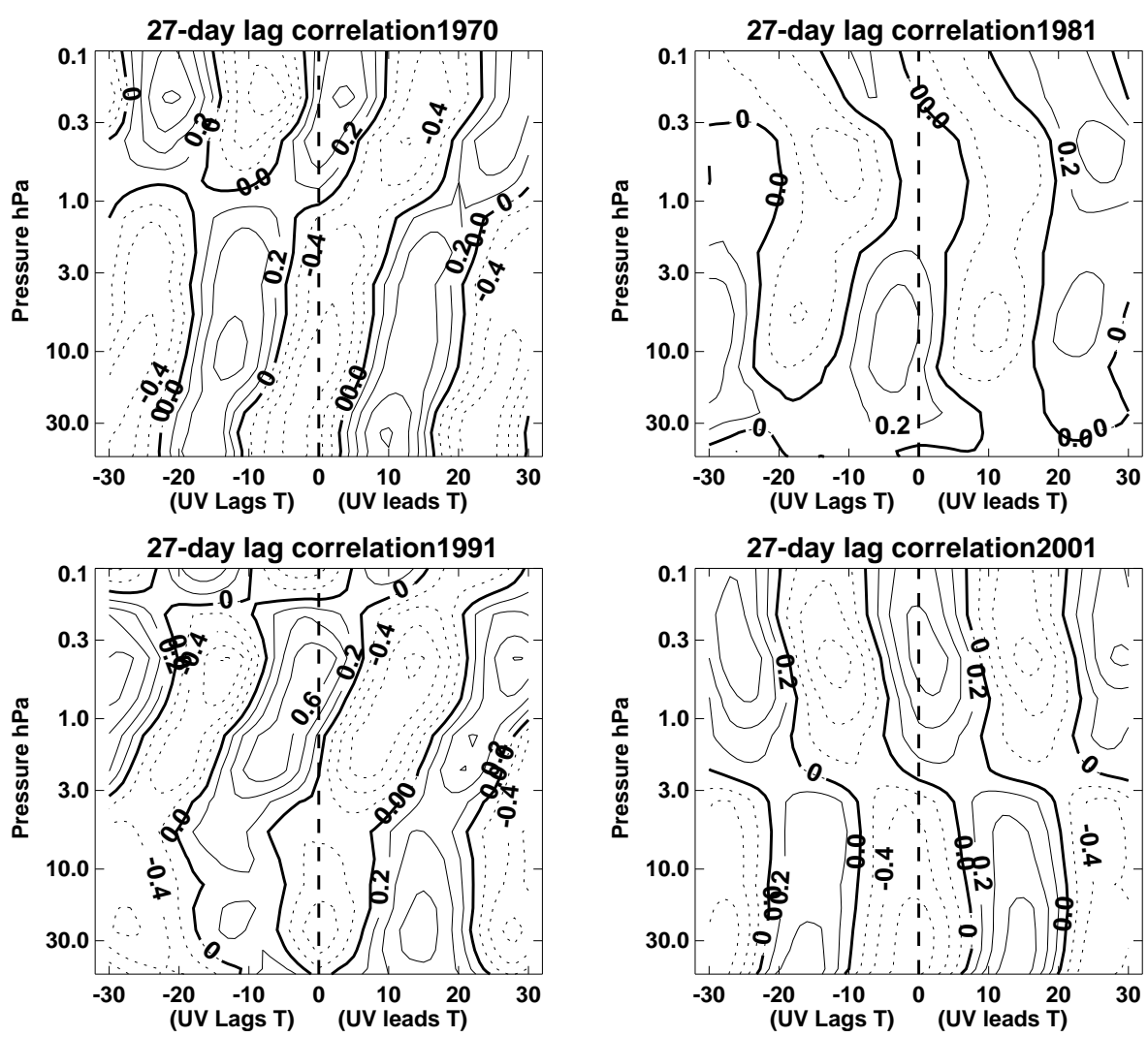

Fig. 3. Lag correlations between temperature and UV averaged over the latitude range $30^{\circ} \mathrm{S}$ to $30^{\circ} \mathrm{N}$ for the 27 day oscillation for the years indicated for the four solar cycles. The contour interval is 0.2 .

more similar to our results for 2001. As noted by Hood and Zhou, the lack of a significant 27-day solar signal response above $2 \mathrm{hPa}$ in Microwave Limb Sounder (MLS) data (Waters, 1989), may be related to the fact that the majority of the ozone soundings were taken at night and therefore cannot respond to day time variations. In contrast, the 3 -D model is a strict zonal average at 00:00 UT, which is very nearly a diurnal average. Observations of the solar signal in 1979-1980 (Hood, 1986; Hood and Cantrell, 1988) are similar to that of the MLS data, except that in this case a significant correlation between ozone and the 27-day UV signal is present in the lower mesosphere where the SBUV data vary diurnally. In general, though, the model response is more dependent on the period analysed than the observations. For example, the 1981 results are about 50\% less than observed for the period November 1980 to September 1982 analysed by Hood and Cantrell.

Lag correlation results for temperature are shown in Fig. 3, which may be compared with Williams et al. (2001), Fig. 4. The results are different in many respects from their Run B, which like our simulations also excludes the 27-day cycle in the radiative terms, and indeed look more similar to their Run A, which includes the radiative term. AMTRAC has larger correlations than UMETRAC (Williams et al.), possibly be- cause the temperature signal is more difficult to detect and requires more 27 day cycles than were simulated with UMETRAC.

The results do not agree well with the observations of Hood and Zhou (1998). This may be due to the small size of the temperature signal, making the detection of a coherent signal in both observations and model results particularly challenging. The temperature would be expected to lag the UV by a greater amount than the ozone, because of the time taken for a radiative response to the ozone. This is more clearly visible in the results for 1970 and 1991 but not present in 1981 and 2001, and not clearly apparent in the observations.

The ozone sensitivity to the $205 \mathrm{~nm}$ flux as a function of altitude is presented in Fig. 4 (cf. Williams et al., 2001, Fig. 3). Each individual Schwabe cycle is very different, although at the phase of maximum correlation, each cycle indicates a peak in the upper stratosphere with a minimum, near zero response in the lower stratosphere. This is similar to the results of Williams et al. for maximum correlation, but the AMTRAC results decrease more substantially with altitude in the upper stratosphere. The peak in the very low stratosphere, below $50 \mathrm{hPa}$ in the results of Williams et al. (2001), is not simulated. In the AMTRAC results, the signal to noise 

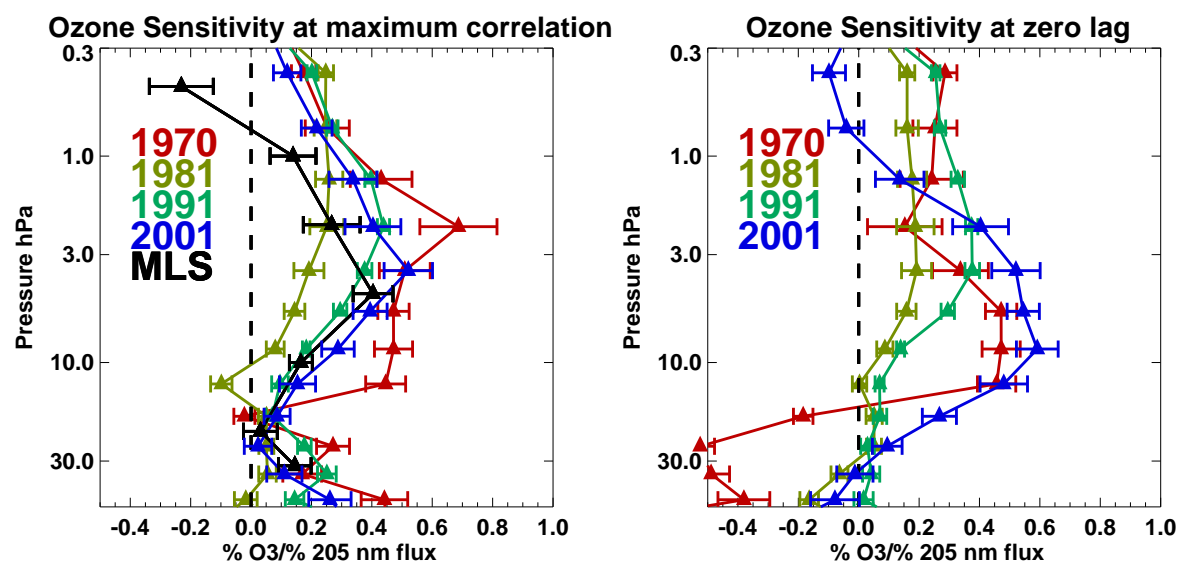

Fig. 4. Ozone sensitivity in $\%$ for each $\%$ change in model $205 \mathrm{~nm}$ flux for the 27 -day solar rotation period for the time at which the correlation between ozone and UV is a maximum correlation (left panel) and at zero lag (right panel). Derived values from MLS data (Hood and Zhou, 1998) for the period 20 October 1991 to 15 July 1994 are given by the black line. The results have been averaged over the latitude range $30^{\circ} \mathrm{S}$ to $30^{\circ} \mathrm{N}$ and over all three ensemble members. The error bars indicate $95 \%$ confidence intervals from the linear regression analysis.

ratio became very small in this part of the atmosphere, so the results are not plotted. The likelihood is that the Williams et al. (2001) result there is not a real effect for the same reason. Rozanov et al. (2006) also found a marked variation in the sensitivity to the year of simulation in a sequence of individual 1-year simulations. Their mean results are also in good agreement with observations, but in the mesosphere their ozone sensitivity is larger than the results obtained here. This could be a result of the simplified mesospheric chemistry in the current work.

The observed ozone sensitivity from Hood and Zhou (1998) peaks at about $0.4 \%$ at $5 \mathrm{hPa}$ (black curve in Fig. 4). The model simulations for 1991 and 2001 are in good agreement with these values, with the 1970 values too high and the 1981 values lower than observed. The values at zero lag (Fig. 4, right panel) also covers a wide range and are similar in magnitude. The values for 1970 are very different to the other years, particularly near $30 \mathrm{hPa}$. This is likely to be due to an interfering dynamical signal rather than a solar impact itself.

A similar analysis for temperature yields the results shown in Fig. 5 (cf. Williams et al., 2001, Fig. 5). The temperature response is very small, typically less than $0.1 \mathrm{~K}$ per $\%$ change in $205 \mathrm{~nm}$ flux. It is questionable whether the signal is statistically significant in much of the domain, although it appears to be slightly positive for maximum correlation. A clear difficulty faced by the modelling technique used here, in which all the known processes are included, is separating small signals from a dataset rich in features. This is of course the problem also faced in the analysis of observations. In contrast, the simulations of Williams et al. were focused more precisely on the 27-day oscillation since background trends in WMGGs, halogens or indeed monthly average solar flux were not imposed. Also, inclusion of the radiative effect of the 27-day oscillation likely enhanced the temperature signal in Williams et al. Rozanov et al. (2006) also have a much larger signal, by about a factor of two compared with that obtained here.

For 1991 the model results below $5 \mathrm{hPa}$ are in good agreement with measurements from MLS (Hood and Zhou, 1998). At $2 \mathrm{hPa}$ and above the observed signal increases to about $0.08 \%$ per $1 \%$ change in $205 \mathrm{~nm}$ flux from MLS. This is the closest year to the analysis year, but there is a large spread in the model results from the different solar cycles. For the late 1970s, Hood (1986) and Hood and Cantrell (1988) suggest that the 27-day temperature solar cycle peaks at about $0.06 \%$ per $1 \%$ change in $205 \mathrm{~nm}$ flux. The upper stratospheric peak in the observations averages at about twice the model value averaged over all the solar cycles. This is probably because of the neglect of the radiative forcing, as well as possibly other unidentified impacts, on the temperature signal.

\subsection{The 11-year Schwabe cycle}

Figure 6 shows the annual mean response of ozone to the solar cycle in \% per 100 units of $F_{10.7}$, together with the $2 \sigma$ uncertainty. A statistically significant solar ozone signal is computed only in the low and middle latitude middle and upper stratosphere, extending to the tropical lower stratosphere. An important feature of these results is the low latitude minimum response near $20 \mathrm{hPa}$. Generally, the results are similar to those observed, for example, the SBUV data from Soukharev and Hood (2006), or the results of Randel and $\mathrm{Wu}$ (2007), but there is too much model variability to discern a definitive solar cycle in a large part of the domain.

The annual mean temperature response as a function of pressure and latitude is shown in Fig. 7. The signal is 

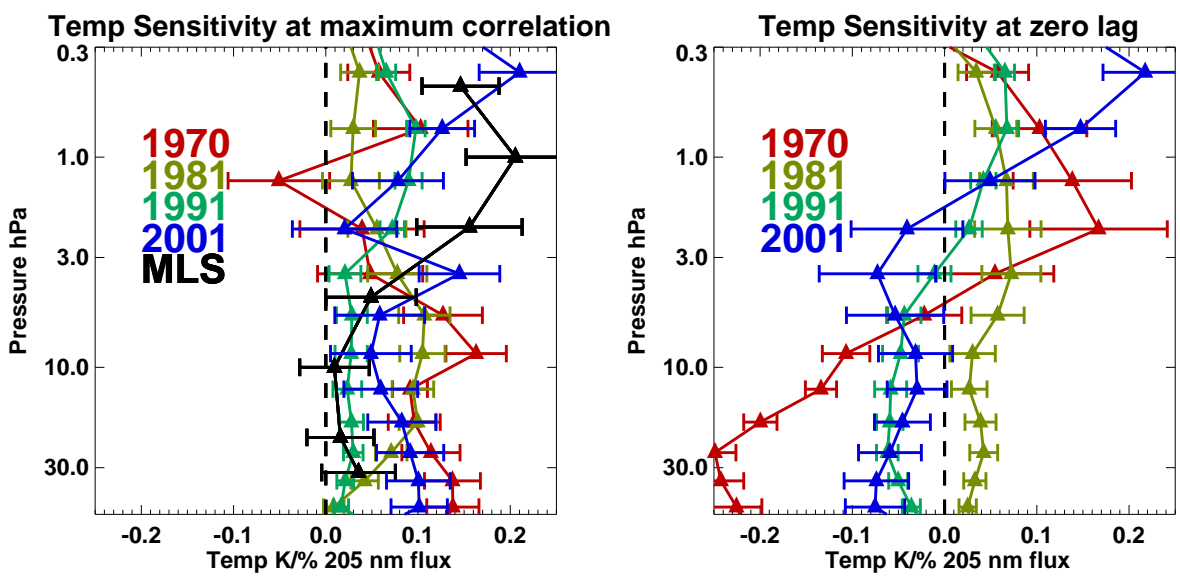

Fig. 5. Temperature sensitivity in $\mathrm{K}$ for each $\%$ change in model $205 \mathrm{~nm}$ flux for the 27 -day solar rotation period for the time at which the correlation between ozone and UV is a maximum correlation (left panel) and at zero lag (right panel). Derived values from MLS data (Hood and Zhou, 1998) for the period 20 October 1991 to 15 July 1994 are given by the black line. The results have been averaged over the latitude range $30^{\circ} \mathrm{S}$ to $30^{\circ} \mathrm{N}$ and over all three ensemble members. The error bars indicate $95 \%$ confidence intervals from the linear regression analysis.
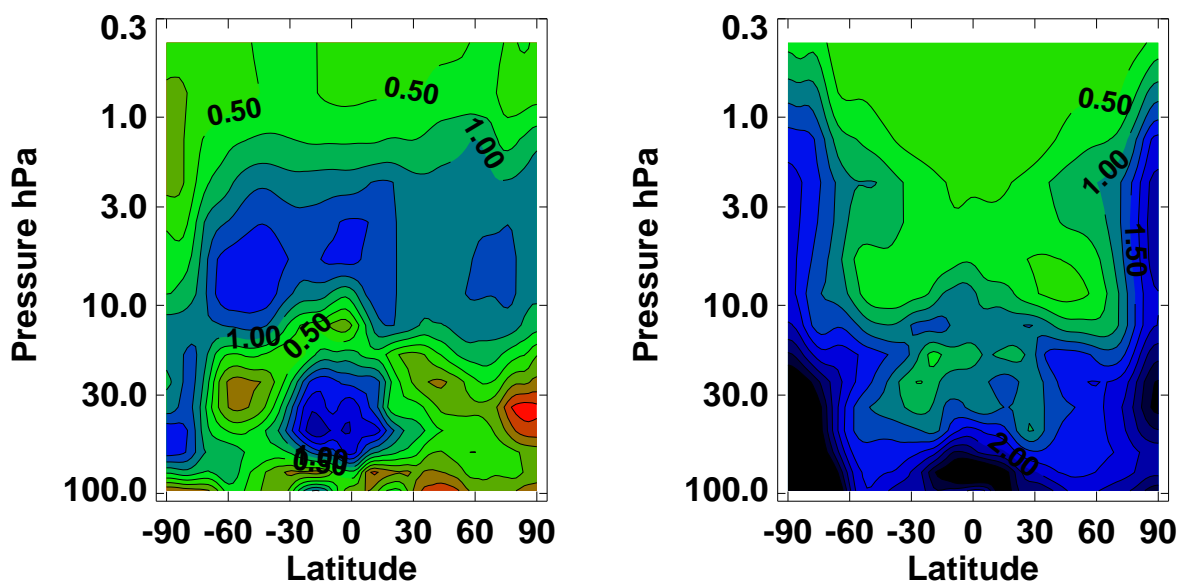

Fig. 6. Left panel: Simulated annual mean ozone solar response in $\%$ per 100 units of $10.7 \mathrm{~cm}$ flux as a function of pressure and latitude. Right panel: $2 \sigma$ uncertainty in the derived solar response. The contour interval is $0.25 \%$ in both panels.

statistically significant above $70 \mathrm{hPa}$ throughout the low and middle latitudes. In high latitudes the lower stratospheric signal is opposite to the upper stratospheric signal, although not all the features are statistically significant. Within the latitude range $30^{\circ} \mathrm{S}$ to $30^{\circ} \mathrm{N}$ the model results are in reasonable agreement with the solar cycle computed from Stratospheric Sounding Unit (SSU) data (Scaife et al., 2000), but outside this latitude range, observations are less reliable and the model diverges from the observations. For the remainder of this paper, we concentrate primarily on the tropical regions where the solar signal in both temperature and ozone can be more clearly defined.

The solar cycle response in the model is analysed by considering the term $b_{3} / \mathrm{O}_{3}$ from the regression analysis. Figure 8 shows the vertical profile of these results, for each season, averaged over all three ensemble members and averaged over the latitude range $25^{\circ} \mathrm{S}$ to $25^{\circ} \mathrm{N}$. For a typical solar cycle, the difference between solar maximum and solar minimum is $125-150$ units, depending on the definition of solar maximum, so the values in Fig. 8 should be multiplied by $1.25-1.50$ for a full solar cycle. However, even on a monthly mean the $10.7 \mathrm{~cm}$ flux at solar maximum can vary substantially. Each season has qualitatively similar results providing confidence in the results, but the most striking feature is the local minimum in the solar response near $20 \mathrm{hPa}$. The demonstration of a statistically significant minimum response does not appear in any other published model results to date (e.g. Shindell et al., 1999; Tourpali et al., 2003; Egorova et al., 2004). Rozanov et al. (2005b) simulated a slight minimum response in this region, but they did not 

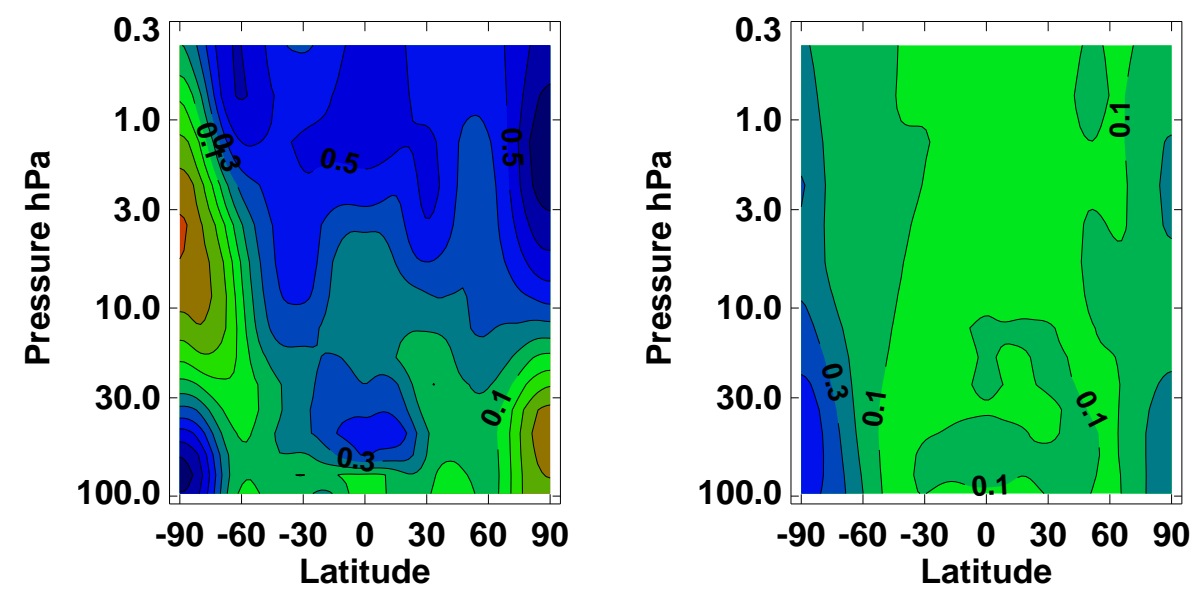

Fig. 7. Left panel: Simulated annual mean temperature solar response in $\mathrm{K}$ per 100 units of $10.7 \mathrm{~cm}$ flux as a function of pressure and latitude. Right panel: $2 \sigma$ uncertainty in the derived solar response. The contour interval is $0.1 \mathrm{~K}$ in both panels.

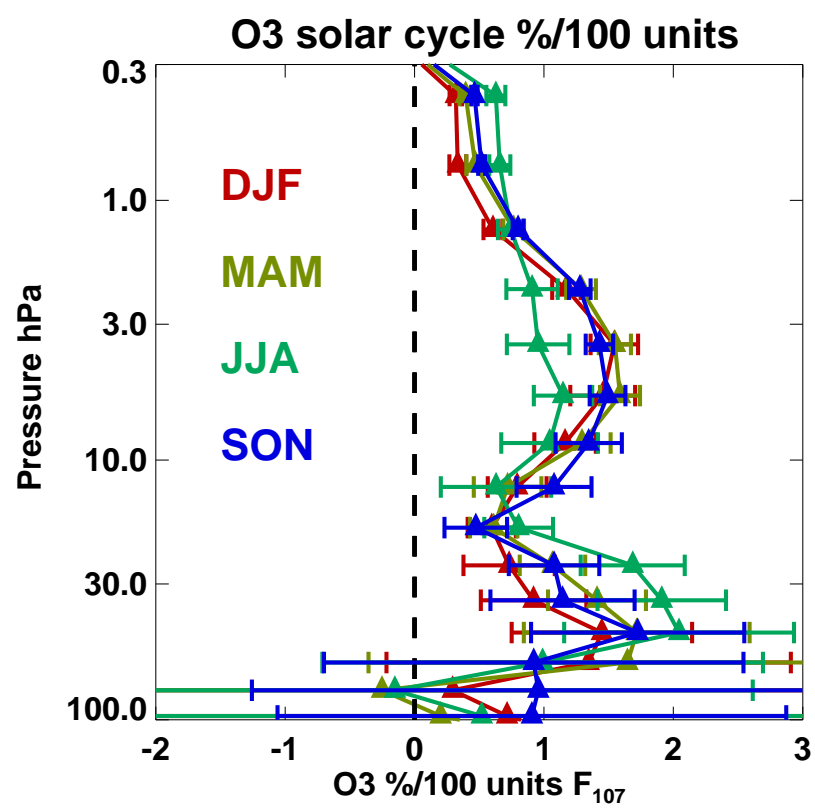

Fig. 8. Simulated seasonal mean ozone solar response in $\%$ per 100 units of $10.7 \mathrm{~cm}$ flux. The results have been averaged over the latitude range $25^{\circ} \mathrm{S}$ to $25^{\circ} \mathrm{N}$ and over all three ensemble members. The error bars indicate $95 \%$ confidence intervals from the linear regression analysis.

comment on the feature or provide any analysis to confirm whether it was realistic or an aspect of random interannual variability.

The annual mean ozone response (Fig. 9) compares well with the observations of Soukharev and Hood (2006). While the observational analysis implies quite large uncertainties, the satellite instruments all yield qualitatively similar results with a minimum in the pressure range $10-25 \mathrm{hPa}$. Its precise location depends on factors such as data resolution. In general, the model agrees reasonably well with HALOE data, but doesn't reproduce the upper stratospheric results of the SAGE data. As in the case of the 27-day cycle, ozone diurnal variations start to become important in the upper stratosphere and mesosphere and the observations represent a biased, day-time solar impact, whereas the model results include night time values. Generally, there are significant discrepancies with SBUV data, but the low vertical resolution of those instruments may have contributed. There may be some sensitivity to the period analysed but in further investigations it was found that the error bars in the measurements were larger than any difference between solar cycles. Tourpali et al. (2007) show comparisons between SBUV data and Umkehr data. The two datasets generally agree well and in most cases suggest that the minimum in tropical response occurs slightly lower than in the satellite data, at approximately $25 \mathrm{~km}(20 \mathrm{hPa})$, close to the minimum in the model solar response. Tourpali et al. also show small horizontal movements in the ozone features, as a function of season of the year, although in view of the small statistical significance of these results we have not analysed the model results in this detail.

The temperature response to the solar cycle is shown in Fig. 10. The signal is very similar in all four seasons, and generally increases to the upper stratosphere. The signal also reflects the ozone signal with a local minimum in the signal near $20 \mathrm{hPa}$. This is consistent with other work (for example Shibata and Kodera, 2005), which showed that the UV effect on temperature was dominant above $5 \mathrm{hPa}$, but the ozone effect was dominant below $5 \mathrm{hPa}$. Model results obtained here agree well with Stratospheric SSU data (reanalysis of results from Scaife et al., 2000) throughout the observed range, but are generally smaller than observed. Analysis of observed temperatures to try to extract the small solar signal is extremely challenging, and other observational analyses give a different estimate for the solar signal (e.g. Labitzke et al., 
2002; Crooks and Gray, 2005). However, these analyses used data assimilation fields which are unreliable for low frequency variability (W. Randel, personal communication, 2006). The model simulations presented in Labitzke et al. also gave a larger temperature solar signal than the results presented here, by about a factor of 2. However, none of the simulations show the tropical ozone minimum response which would tend to reduce the temperature response from ozone in the lower to middle stratosphere.

\section{Analysis and results for fixed solar phase}

It is plausible that the tropical response is an artifact of the statistical analysis or that the ozone sensitivity may be a nonlinear function of the solar phase. Hence data from solar maxima and minima may give extreme or different results. To consider this, we repeat the previous model ozone analysis (Fig. 9) using model data from just those years corresponding to solar maxima and minima (1964, 1970, 1976, 1981, 1986, 1991, 1996, 2001). Considering all three ensemble members gives 12 years for solar maximum and 12 years for solar minimum. Results for the domain $25^{\circ} \mathrm{S}$ to $25^{\circ} \mathrm{N}$ are shown in Fig. 11 for the annual average, together with the results using all solar phases. The results are in agreement below $20 \mathrm{hPa}$, and above $2 \mathrm{hPa}$ but diverge from each other in the middle stratosphere. Despite larger uncertainties in examining a limited sample of the period, it would seem that the lower stratospheric minimum is a robust feature of these model results. Nonetheless, with the analysis presented here, it would seem that the differences in the middle to upper stratosphere are statistically significant, but it should be cautioned that the analysis is based on just 4 solar cycles. Processes not included in the regression analysis, such as transport and chemical changes that cannot be represented as simple trend terms, may have contributed to these differences. To obtain a clearer signal during the solar cycle, we examine results from fixed phase simulations (SL2000 and SL2000B) as previously completed by other workers (e.g. Brasseur, 1993; Haigh, 1994; Shindell et al., 1999; Tourpali et al., 2003; Egorova et al., 2004).

The ozone difference between solar maximum and solar mean for timeslice runs for the year 2000 (experiments SL2000B and SL2000 of Table 1) is shown in Fig. 12. In the annual mean, the results are very different for the fixed solar phase results as compared with the transient simulations (Fig. 12, red curve). In particular, the middle stratospheric peak is slightly larger than in the transient simulations, and a minimum no longer occurs near $20 \mathrm{hPa}$. A slight minimum occurs near $50 \mathrm{hPa}$ in the fixed phase results, but this is not statistically significant. These results are consistent with previous simulations of other models with fixed phase solar forcing (see e.g. Soukharev and Hood, 2006) regarding their inability to simulate the lower stratospheric minimum. Below about $50 \mathrm{hPa}$, the model values have a large uncertainty,
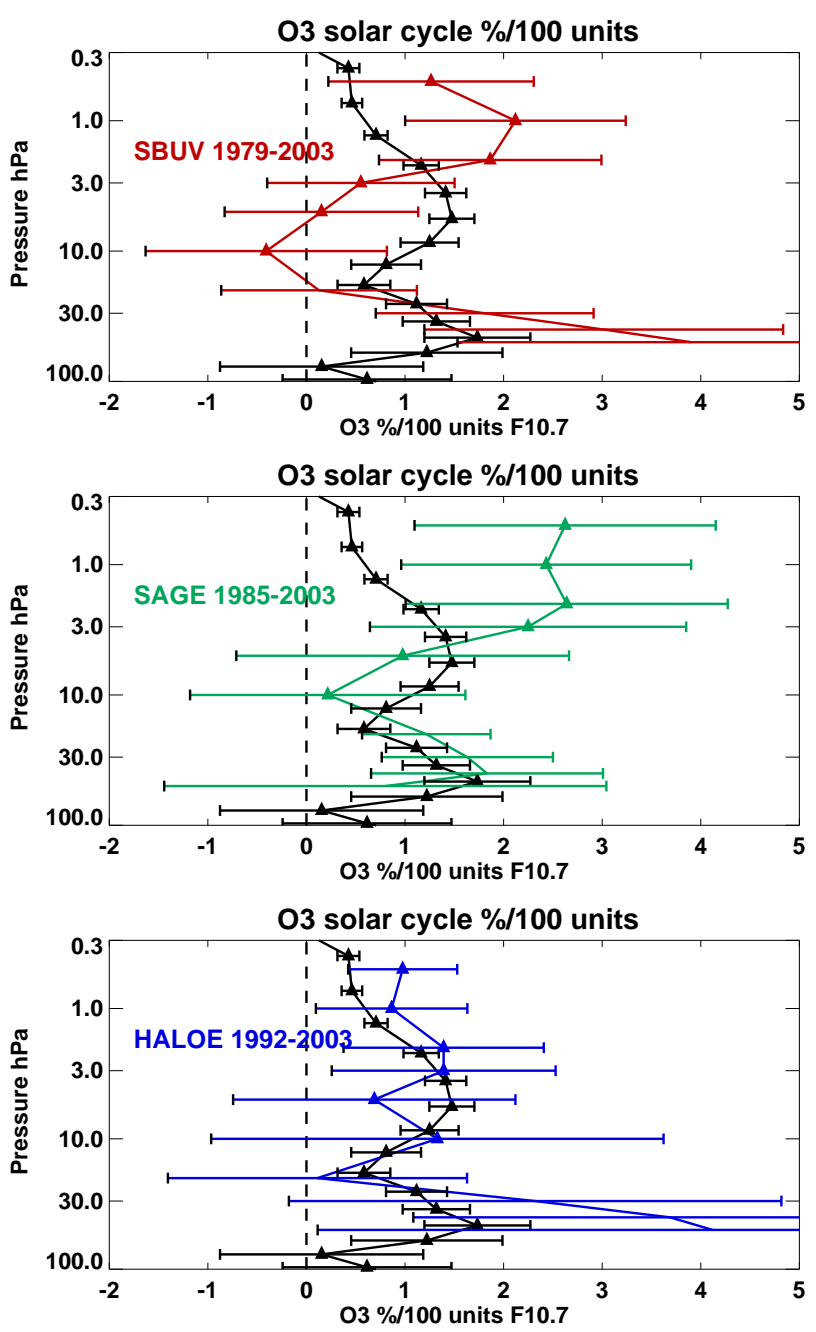

Fig. 9. Annual mean ozone solar response in $\%$ per 100 units of $10.7 \mathrm{~cm}$ flux in comparison with satellite measurements. The results have been averaged over the latitude range $25^{\circ} \mathrm{S}$ to $25^{\circ} \mathrm{N}$ and over all three ensemble members. The error bars indicate $95 \%$ confidence intervals from the linear regression analysis. Black lines: model results; coloured lines: satellite results as indicated, from Soukharev and Hood (2006).

presumably due to model dynamical variability. Most seasons produced similar results, although during the Northern summer and autumn periods the results are more similar to the annual mean transient results in producing a smaller peak response near $3 \mathrm{hPa}$.

\section{The solar cycle impact on tropical upwelling}

To investigate the impact of dynamics on the results, we examine the solar cycle in tropical upwelling. The tropical mass upwelling is being increasingly recognised as an important proxy for the strength of the Brewer-Dobson circulation, which has been simulated to increase over time in most 

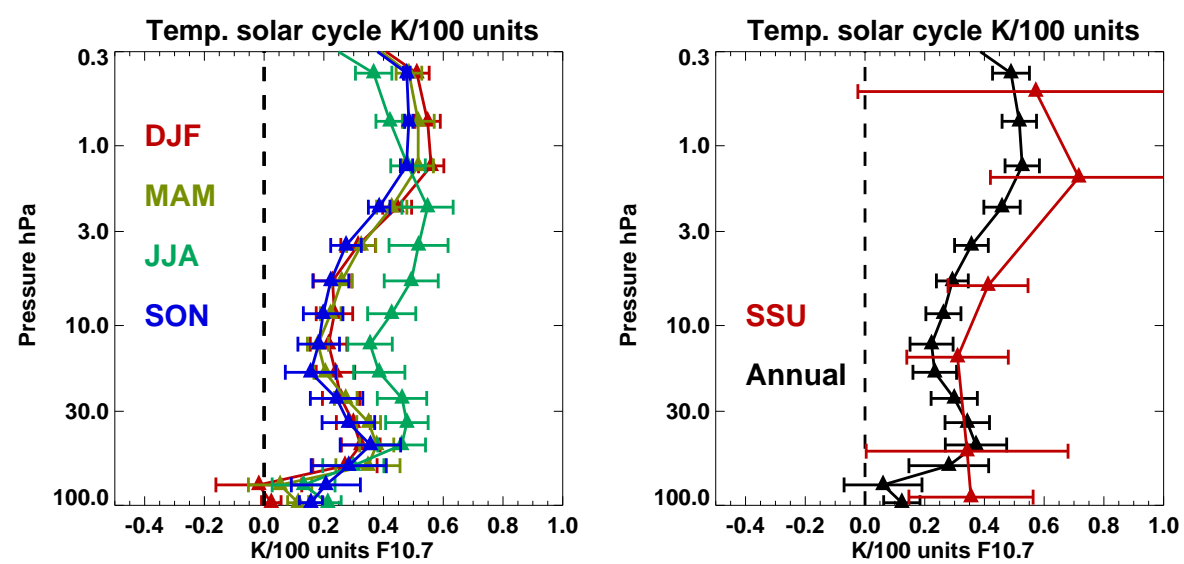

Fig. 10. Seasonal (left panel) and annual (right panel) temperature response to the solar cycle in $\%$ per 100 units of $10.7 \mathrm{~cm}$ flux. The results have been averaged over the latitude range $25^{\circ} \mathrm{S}$ to $25^{\circ} \mathrm{N}$ and over all three ensemble members. The error bars indicate $95 \%$ confidence intervals from the linear regression analysis. The SSU data from Scaife et al. (2000) were reprocessed by using the regression Eq. (5) and cover January 1980 to December 1997.

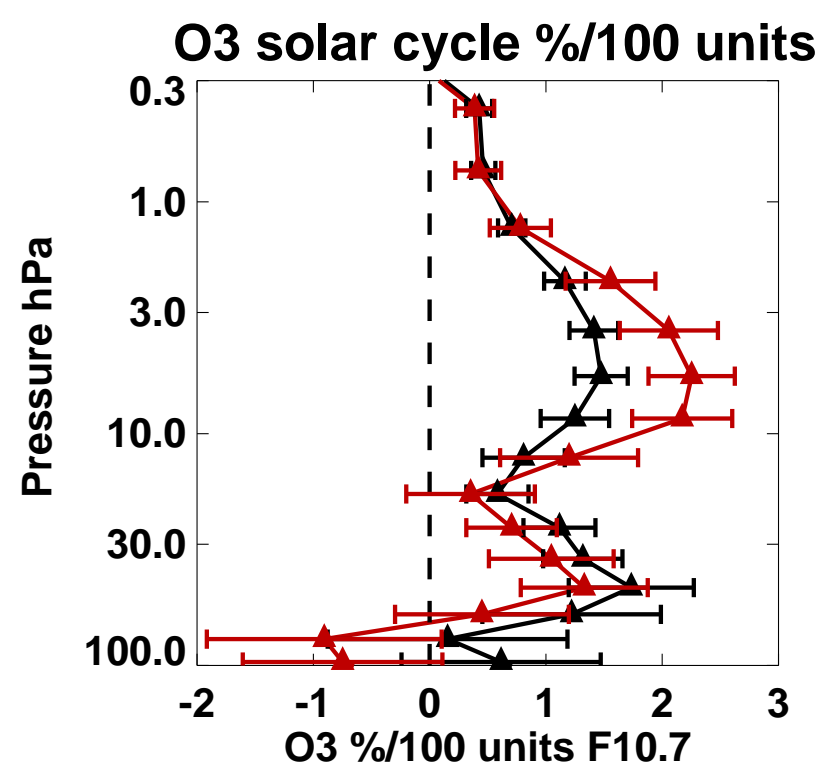

Fig. 11. Annual mean ozone solar response in $\%$ per 100 units of $10.7 \mathrm{~cm}$ flux. The black line indicates the results using model data from all solar phases, the red line indicates the results obtained when only the calendar years of solar maximum and solar minimum were used in the regression analysis. The results are averaged over the latitude range $25^{\circ} \mathrm{S}$ to $25^{\circ} \mathrm{N}$ and over all three ensemble members. The error bars indicate the $95 \%$ confidence intervals obtained from the regression analysis.

models (Butchart and Scaife, 2001; Butchart et al., 2006). In the transient simulations presented here, the mass upwelling also increases and there is also a simple relationship with the inverse age of air (Austin and $\mathrm{Li}, 2006$ ). The consequences are that over time chemical constituents had a shorter stratospheric timescale and the large scale tropical ascent rate in- creased. As in the above works, the tropical upward mass flux is determined from the mass streamfunction by integrating between the latitudes over which the flux is upwards, approximately $30^{\circ} \mathrm{S}$ to $30^{\circ} \mathrm{N}$.

The response of the tropical upwelling to the solar cycle in the simulations is shown in Fig. 13. In both sets of simulations, the theoretical uncertainties in the solar forcing terms are very large, precluding definitive statements. For example, neither results differ significantly from zero while for the seasonal variation, both results are similar below $3 \mathrm{hPa}$ in showing a generally positive upwelling solar signal during Northern autumn and a negative upwelling solar signal during Northern summer (not shown). An indirect measure of transport is the concentration of water vapour (e.g. Mote et al., 1996). Again, because of the large variability we show only the annual mean solar cycle in the two sets of simulations (Fig. 14), averaged between $30^{\circ} \mathrm{S}$ and $30^{\circ} \mathrm{N}$. In this case, the fixed phase runs indicate a slight increase in water vapour concentrations and the transient runs indicate a decrease. Results in the mesosphere should be ignored as the model chemistry was not designed to be realistic there. Nonetheless, below about $3 \mathrm{hPa}$, the sensitivities to the solar cycle are marginally statistically significant at the $95 \%$ confidence level.

Interpretation of these results is complex. The change in tropopause temperature (Fig. 10) results in a saturated vapor pressure increase of about $3 \%$ but at the hygropause, the model results show little sensitivity to the solar cycle. However, a reduction in water vapour due to the solar cycle occurs at slightly higher altitudes, implying increased upward motion, since the water vapour gradient is upwards. Below $10 \mathrm{hPa}$, upward motion decreases ozone and above $10 \mathrm{hPa}$ upward motion increases ozone slightly, because of the direction of the ozone gradient. The photochemical timescale 

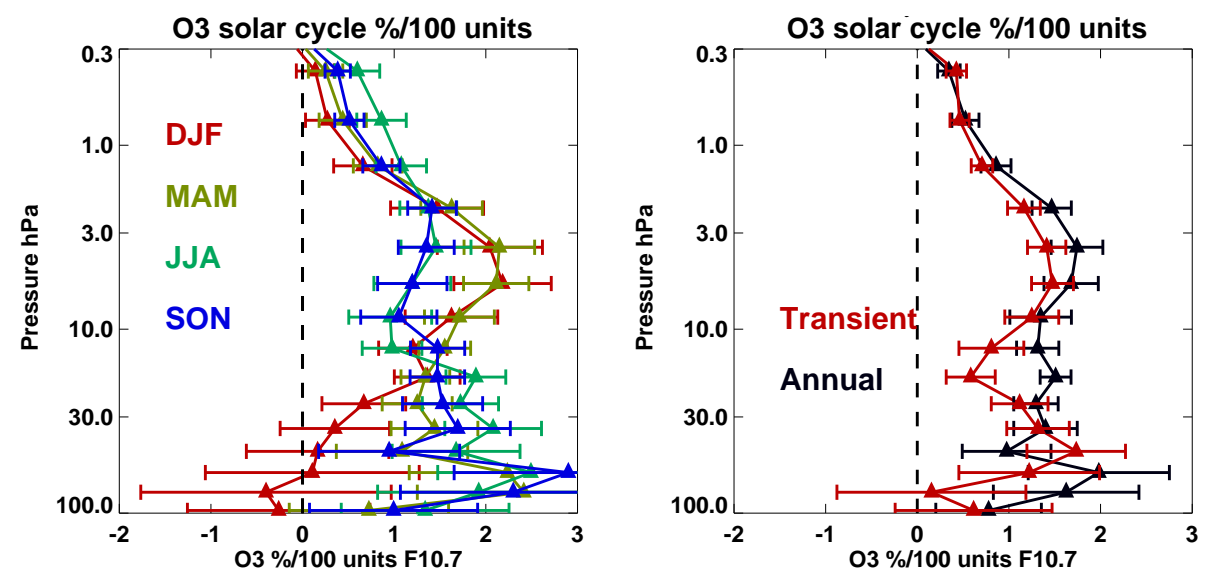

Fig. 12. Ozone solar response in $\%$ per 100 units of $10.7 \mathrm{~cm}$ flux for solar maximum - solar mean from the timeslice runs SL2000B and SL2000. The results are an average over the latitude range $25^{\circ} \mathrm{S}$ to $25^{\circ} \mathrm{N}$ for the different seasons (left panel) and for the annual average (right panel). Also included in the right hand panel are the results for the transient experiments in the annual average. All the error bars denote the $95 \%$ confidence intervals.

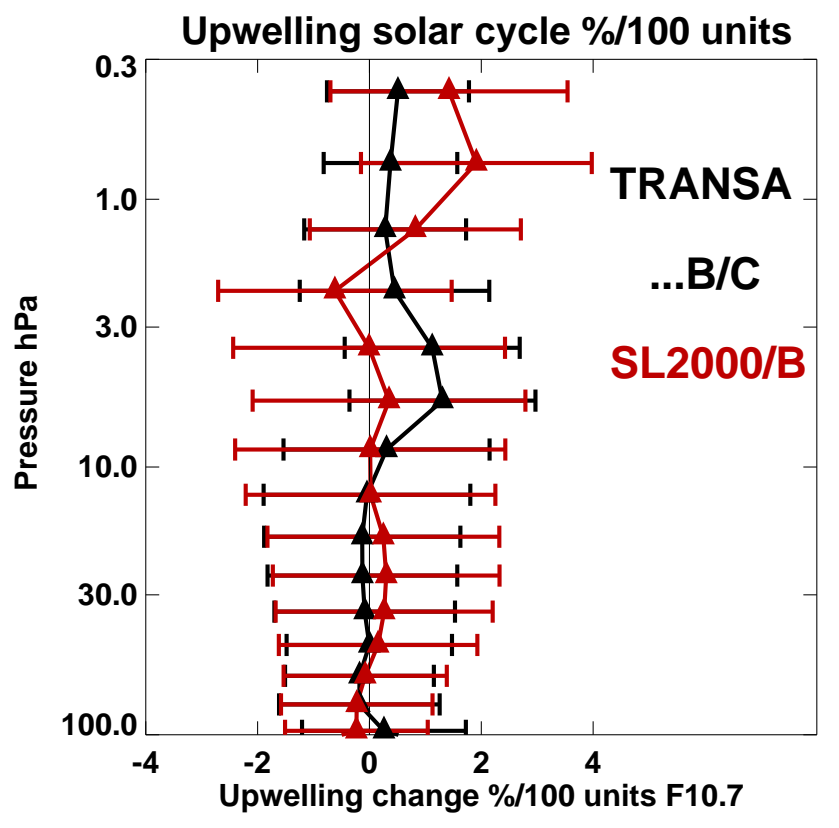

Fig. 13. Annual mean solar response in the tropical upwelling in \% per 100 units of $10.7 \mathrm{~cm}$ flux in the transient simulations TRANSA, TRANSB and TRANSC (black) in comparison with the solar signal in simulations SL2000 and SL2000B (red).

decreases rapidly with altitude so that vertical motion becomes less effective. Consequently, the decrease in ozone due to the solar cycle (Fig. 9) and its absence in the fixed phase runs (Fig. 12) may be related to the decrease in water vapour seen in Fig. 14. There are two problems with this argument, (i) there is no clear increase in tropical upwelling itself (Fig. 13) and (ii) the proposed dynamical changes - an increased in upwelling for high solar flux - is inconsistent

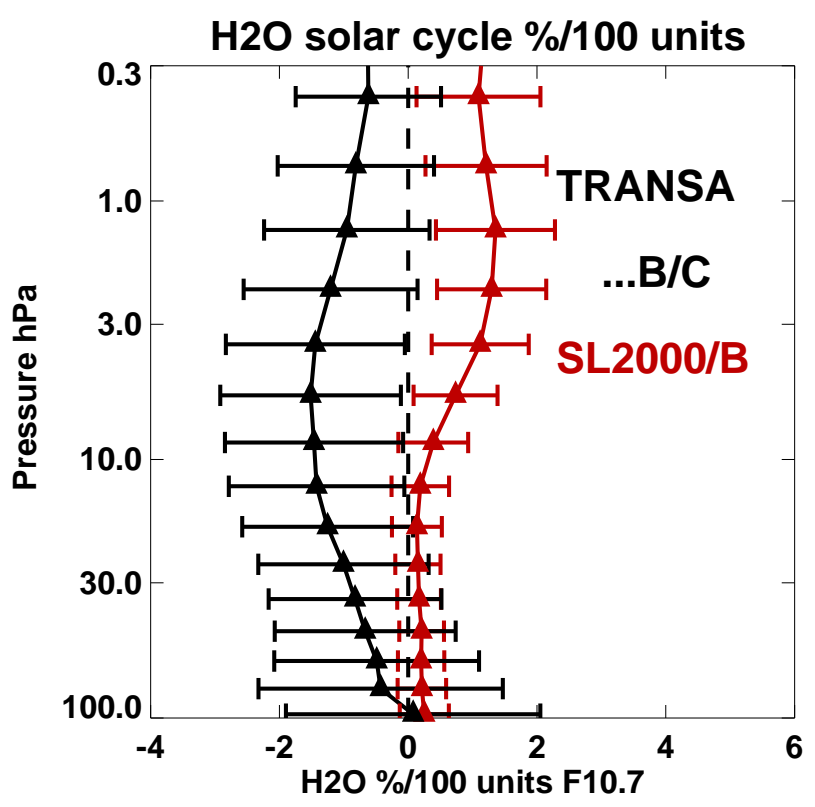

Fig. 14. As Fig. 13, but for the water vapour concentration.

with the dynamical viewpoint of Kodera and Kuroda (2002), based on a simplified model. The implications on temperature of upward motion would be to increase the adiabatic cooling relative to the direct radiative effect. There would also be an indirect radiative effect from the solar induced ozone change. These impacts on ozone and temperature are consistent with the model results shown in Figs. 9 and 10. 


\section{Conclusions}

A coupled chemistry climate model has been used to simulate the impacts of the 27-day solar rotation cycle and the 11-year Schwabe cycle on ozone and temperature.

The 27-day results were analysed for a period of one calendar year at the maximum of each of the 11-year Schwabe cycles when the response was largest. The results were found to vary from one solar cycle to the next. Good agreement was found particularly in ozone between the model results and observations of Zhou et al. (1997) and Hood and Zhou (1998). Depending on the year chosen, the ozone results demonstrated the downward propagation of the 27-day oscillation phase in some cases but with little phase propagation in other years. The ozone sensitivity to the 27-day oscillation was also quantitatively well reproduced, peaking at about $0.4 \%$ per $1 \%$ change in $205 \mathrm{~nm}$ flux. In the model, the peak occurred at higher altitude and in the upper stratosphere the model diverged from the observations, but this may be an error in the observations, which are not strict diurnal averages. The temperature response to the 27-day cycle is small, typically less than $0.5 \mathrm{~K}$, and is difficult to extract from both model and observations. Although as a percentage, the temperature sensitivity varied more than the ozone between solar cycles, the temperature response for 1991 agreed surprisingly well with observations for 1991-1994 (Hood and Zhou, 1998). However, for other years for which measurements exist (Hood, 1986; Hood and Cantrell, 1988) the model results agree only qualitatively with observations. This suggests the need for a further analysis of the 27-day solar cycle in models and the factors contributing to it. It is likely that the different strengths of the Schwabe cycle may be a contributing factor due to the presence of possible nonlinearities in the chemistry.

For the 11-year solar cycle in the lower and middle stratosphere, we show good agreement between model results and observations in the transient simulations, without including energetic electron precipitation effects. In particular, the tropically averaged results demonstrated a statistically significant minimum in ozone response near $20 \mathrm{hPa}$, which has not previously been published (e.g. Shindell et al., 1999; Soukharev and Hood, 2006). Examination of the ozone values just for the solar maxima and solar minima during the 135 years of simulations ("fixed solar phase analysis") resulted in a higher ozone response in the middle and upper stratosphere while the minimum in ozone response in the lower stratosphere was largely unaffected. In a final set of experiments, with fixed solar phase applied continuously during the runs, as well as fixed climatological SSTs, the ozone response was quite different to the results of the transient runs with the absence of the lower stratospheric minimum. These results are generally consistent with the transient simulations reported by Eyring et al. (2006) which have at the time of writing been analysed for a solar cycle signal (K. Matthes, R. Garcia, K. Shibata, E. Rozanov, personal communications, 2006).

The temperature response to the 11-year solar cycle was determined in large part by the ozone. Comparison with measurements proved to give mixed results as it is hampered by the need to obtain instrument stability of better than a few tenths of a K over a decade or more. Nonetheless, the results agree reasonably well over the pressure range 1 to $30 \mathrm{hPa}$ with the results obtained from one of the satellite datasets that has arguably been best scrutinised (see Nash and Brownscombe, 1983; Scaife et al., 2000).

Although solar cycle effects are small, about an order of magnitude smaller than ozone changes over the last few decades due to chlorine change, accurate simulation of these processes provides confidence in the predictions of the models for the future. One of the significant changes introduced in AMTRAC which is not present in many previous simulations exploring the solar cycle, is the fact that the observed monthly varying Schwabe and temporally varying 27 -day cycles are imposed, whereas previous simulations have been completed with a fixed solar phase (Labitzke et al., 2002; Tourpali et al. 2003; Williams et al., 2000 etc.).

It has been suggested that interactions with the quasibiennial oscillation (QBO) may be responsible for the tropical minimum in the ozone solar cycle response. This has been attributed either to a simple interference of the QBO in the statistical analysis (Lee and Smith, 2003) or to a real solar cycle modulation of the QBO itself (e.g., McCormack, 2003). The results obtained here without a model QBO would suggest that this is not essential. Also, observational studies (Soukharev and Hood, 2006), indicate a broad minimum over a wide latitude range consistently occurring over several solar cycles, which is not easily explained by the QBO alone. Nevertheless, a pronounced local minimum ozone solar cycle response is often obtained at $10 \mathrm{hPa}$ centered on the equator (see Figs. 6 and 7 of Soukharev and Hood). This pronounced minimum does suggest a partial role for the QBO in producing at least some of the observed ozone response minimum. This possibility should be investigated in the future using models that simulate a realistic QBO.

It should also be recognised that the solar cycle is by no means sinusoidal in shape (Fig. 1). This may give rise to assymetries also in the dynamics, as well as additional processes with timescales shorter than the 11-year period. Examination of the tropical upwelling, which is a strong candidate for a dynamical response to the solar cycle, proved to be inconclusive in the simulations presented here due at least in part to the large uncertainties in determining the solar signal from a somewhat noisy field. However, simulated water vapour values contained a solar cycle indicative of enhanced upward motion during high solar fluxes. There is a possibility that this increase may have been driven by SSTs, since as noted by White et al. (2003), global SSTs have been phase locked to the solar cycle. Solar induced changes in tropical SSTs could affect the tropical tropopause temper- 
ature (T. Reichler, personal communication, 2006), as detected in observations on the 27-day time scale (Hood, 2003). Nonetheless, it is not clear that the model is simulating the correct magnitude or even sign of this effect, since theoretical and observational evidence favors relative downwelling in the tropics near solar maxima (Kodera and Kuroda, 2002; Hood and Soukharev, 2003). Further long simulations are therefore needed both with different models as well as longer and more simulations with the same model to extract more reliable statistics from chaotic fields.

In summary, the improved agreement with observations in our simulations compared with previous work has arisen from the specification of all phases of the 11-year solar cycle as well as time varying SSTs. These two components were absent from control runs in which simulated ozone was consistent with previous simulations. A plausible argument has been presented as to why the SSTs could be playing a major role, an issue which could be examined by completing further simulations with a full solar cycle but climatological SSTs.

Acknowledgements. J. Austin's research was supported by the Visiting Scientist Program at the NOAA Geophysical Fluid Dynamics Laboratory, administered by the University Corporation for Atmospheric Research. We would like to thank D. Schwarzkopf, L. Horowitz and two anonymous reviewers for their useful comments on earlier drafts of the paper.

Edited by: V. Fomichev

\section{References}

Anderson, J. L., Balaji, V., Broccoli, A. J., et al.: The new GFDL global atmosphere and land model AM2/LM2: Evaluation with prescribed SST simulations, J. Climate, 17, 4641-4673, 2004.

Austin J.: A three-dimensional coupled chemistry-climate model simulation of past stratospheric trends, J. Atmos. Sci., 59, 218232, 2002

Austin, J. and Li, F.: On the relationship between the strength of the Brewer-Dobson circulation and the age of stratospheric air, Geophys. Res. Lett., 33, L17807, doi:10.1029/2006GL026867, 2006.

Austin, J. and Wilson, R. J.: Ensemble simulations of the decline and recovery of stratospheric ozone, J. Geophys. Res., 111, D16314, doi:10.1029/2005JD006907, 2006.

Austin, J., Wilson, R. J., Li, F., and Vömel, H.: Evolution of water vapor concentrations and stratospheric age of air in coupled chemistry-climate model simulations, J. Atmos. Sci., 64, 905921, 2007

Baldwin, M. P. and Dunkerton, T. J.: Observations and statistical simulations of a proposed solar cycle/QBO/weather relationship, Geophys. Res. Lett., 16, 863-866, 1989.

Brasseur, G.: The response of the middle atmosphere to long-term and short-term solar variability: A two-dimensional model, J. Geophys. Res., 98, 23 079-23 090, 1993.
Butchart, N. and Scaife, A. A.: Removal of chlorofluorocarbons by increased mass exchange between the stratosphere and the troposphere in a changing climate, 410, 799-802, 2001.

Butchart, N., Scaife, A. A., Bourqui, M., de Grandpré, J., Hare, S. H. E., Kettlebororough, J., Langematz, U., Manzini, E., Sassi, F., Shibata, K., Shindell, D., and Sigmond, M.: Simulations of anthropogenic change in the strength of the Brewer-Dobson circulation, Clim. Dyn., 27(7-8), 727-741, 2006.

Callis, L. B., Natarajan, M., and Lambeth, J. D.: Solar-atmosphere coupling by electrons (SOLACE) 3. Comparisons of simulations and observations, 1979-1997, issues and implications, J. Geophys. Res., 106, 7523-7539, 2001.

Chandra, S., McPeters, R. D., Planet, W., and Nagatani, R. M.: The 27 day solar UV response of stratospheric ozone: solar cycle 21 vs. solar cycle 22, J. Atmos. Terr. Phys., 56, 1057-1065, 1994.

Chen, L., London, J., and Brasseur, G.: Middle atmosphere ozone and temperature responses to solar irradiance variations over $27-$ day periods, J. Geophys. Res., 102, 29957-29 979, 1997.

Coughlin, K. and Tung, K. K.: Eleven-year solar cycle signal throughout the lower atmosphere, J. Geophys. Res., 109, D21105, doi:10.0129/2004JD004873, 2004.

Crooks, S. A. and Gray, L. J.: Characterization of the 11-year solar signal using a multiple regression analysis of the ERA-40 dataset, J. Climate, 18, 996-1015, 2005.

Egorova, T., Rozanov, E., Manzini, E., Haberreiter, M., Schmutz, W., Zubov, V., and Peter, T.: Chemical and dynamical response to the 11-year variability of the solar irradiance simulated with a chemistry-climate model, Geophys. Res. Lett., 31, L06119, doi:10.1029/2003GL019294, 2004.

Eyring, V., Butchart, N., Waugh, D. W., et al.: Assessment of temperature, trace species and ozone in chemistry-climate model simulations of the recent past, J. Geophys. Res., 111, D22308, doi:10.0129/2006JD007327, 2006.

Fleming, E. L., Chandra, S., Jackman, C. H., Considine, D. B., and Douglass, A. R.: The middle atmospheric response to short and long term solar UV variations: analysis of observations and 2D model results, J. Atmos. Terr. Phys., 57, 333-365, 1995.

Frölich, C.: Observations of irradiance measurements, Space Sci. Rev., 94, 15-24, 2000.

Haigh, J. D.: The role of stratospheric ozone in modulating the solar radiative forcing of climate, Nature, 370, 544-546, 1994.

Hershel, W.: Observations tending to investigatethe nature of the sun, in order to find the causes or symptoms of its variable emission of light and heat, with the remarks on the use that may possibly be drawn from solar observations, Phil. Trans, Roy. Soc. London, 91, 265-318, 1801.

Hood, L. L.: Coupled stratospheric ozone responses to short-term changes in solar ultraviolet flux: an analysis of Nimbus 7 SBUV and SAMS data, J. Geophys. Res., 91, 5264-5276, 1986.

Hood, L. L.: Thermal response of the tropical tropopause region to solar ultraviolet variations, Geophys. Res. Lett., 23, 2215, doi:10.1029/2003GL018364, 2003.

Hood, L. L. and Cantrell, S.: Stratospheric ozone and temperature responses to short term solar ultraviolet variations: reproducibility of low-latitude response measurements, Ann. Geophys., 6, 525-530, 1988, http://www.ann-geophys.net/6/525/1988/.

Hood, L. L. and McCormack, J. P.: Components of interannual ozone change based on Nimbus 7 TOMS data, Geophys. Res. 
Lett., 19, 2309-2312, 1992.

Hood, L. L. and Soukharev, B. E.: Quasi-decadal variability of the tropical lower stratosphere: The role of extratropical wave forcing, J. Atmos. Sci., 60, 2389-2403, 2003.

Hood, L. L. and Soukharev, B. E.: Solar induced variations of odd nitrogen: multiple regression analysis of UARS HALOE data, Geophys. Res. Lett., 33, L22805, doi:10.1029/2006GL028122, 2006.

Hood, L. L. and Zhou, S.: Stratospheric effects of 27-day solar ultraviolet variations: an analysis of UARS MLS ozone and temperature data, J. Geophys. Res., 103, 3629-3638, 1998.

Kodera, K. and Kuroda, Y.: Dynamical response to the solar cycle, J. Geophys. Res., 107(D24), 4749, doi:10.1029/2002JD002224, 2002.

Labitzke, K., Austin, J., Butchart, N., Knight, J., Takahashi, M., Nakamoto, M., Nagashima, T., Haigh, J., and Williams, V.: The global signal of the 11-year solar cycle in the stratosphere: observations and model results, J. Atmos. Solar Terr. Phys., 64, 203210, 2002.

Langematz, U., Grenfell, J. K., Matthes, K., Mieth, P., Kunze, M., Steil, B., and Brühl, C.: Chemical effects in 11-year solar cycle simulations with the Freie Universität Berlin Climate Middle Atmosphere Model with online chemistry (FUB-CMAM-CHEM), Geophys. Res. Lett., 32, L13803, doi:10.1029/2005GL022686, 2005.

Lean, J., Rottman, G., Harder, J., and Kopp, G.: SORCE contributions to new understanding of global change and solar variability, Solar Phys., 203, 27-53, 2005.

Lee, H. and Smith, A. K.: Simulation of the combined effects of solar cycle, quasi-biennial oscillation, and volcanic forcing on stratospheric ozone changes in recent decades, J. Geophys. Res., 108(D2), 4049, doi:10.1029/2001JD001503, 2003.

McCormack, J. P.: The influence of the 11-year solar cycle on the quasi-biennial oscillation, Geophys. Res. Lett., 30, 2162, doi:10.1029/2003GL018314, 2003.

Mote, P. W., Rosenlof, K. H., McIntyre, M. E., Carr, E. S., Gille, J. C., Holton, J. R., Kinnersley, J. S., Pumphrey, H. C., Russell III, J. M., and Waters, J. W.: An atmospheric tape recorder: the imprint of tropical tropopause temperatures on stratospheric water vapor, J. Geophys. Res., 101, 3989-4006, 1996.

NAG: NAG Library, Mark 19, Copyright National Algorithms Group Limited, 1999.

Nash, J. and Brownscombe, J. L.: Validation of the stratospheric sounding unit, Adv. Space Res., 2, 59-62, 1983.

Randel, W. and Wu, F.: A stratospheric ozone profile data set for 1979-2005: variability, trends, and comparisons with ozone column data, J. Geophys. Res., 111, in press, doi:10.1029/2006JD007339, 2007.

Rottman, G.: Solar ultraviolet irradiance and its temporal variation, J. Atmos. Sol.-Terr. Phys., 61, 37-44, 1999.

Rottman, G. J., Woods, T. N., and Sparn, T. P.: SOLar STellar Irradiance Comparison Experiment I: 1. instrument design and operation, J. Geophys. Res., 98, 10 667-10 677, 1993.
Rozanov, E., Callis, L., Schlesinger, M., Yang, F., Andronova, N., and Zubov, V.: Atmospheric response to $\mathrm{NO}_{\mathrm{y}}$ source due to energetic electron precipitation, Geophys. Res. Lett, 32, L14811, doi:10.1029/2005GL023041, 2005a.

Rozanov, E., Schraner, M., Egorova, T., Ohmura, A., Wild, M., Schmutz, W., and Peter, T.: Solar signal in atmospheric ozone, temperature and dynamics simulated with CCM SOCOL in transient mode, Mem. S.A. It., 76, 876-879, 2005b.

Rozanov, E., Egorova, T., Schmutz, W., and Peter, Th.: Simulation of the stratospheric ozone and temperature response to the solar irradiance variability during sun rotation cycle, J. Atmos. SolarTerr. Phys., 68, 2203-2213, 2006.

Scaife, A. A., Austin, J., Butchart, N., Pawson, S., Keil, M., Nash, J., and James, I. N.: Seasonal and interannual variability of the stratosphere diagnosed from UKMO TOVS analyses, Quart. J. Roy. Meteorol. Soc., 126, 2585-2604, 2000.

Schwabe, H.: Solar Observations during 1843, Astronomische Nachrichten, 20, no. 495, 1843.

Shibata, K. and Kodera, K.: Simulation of radiative and dynamical responses of the middle atmosphere to the 11-year solar cycle, J. Atmos. Sol. Terr. Phys., 67, 125-143, 2005.

Shindell, D., Rind, D., Balachandran, N., Lean, J., and Lonergan, P.: Solar cycle variability, ozone, and climate, Science, 284, 305308, 1999.

Soukharev, B. E. and Hood, L. L.: The solar cycle variation of stratospheric ozone: multiple regression analysis of long-term satellite data sets and comparisons with models, J. Geophys. Res., 111, D20314, doi:10.1029/2006JD007107, 2006.

Tourpali, K., Schurmans, C. J. E., von Dorland, R., Steil, B., and Brühl, C.: Stratospheric and tropospheric response to enhanced solar UV radiation: A model study, Geophys. Res. Lett., 30, 1231, doi:10.1029/2002GL016650, 2003.

Tourpali, K., Zerefos, C. S., Balis, D. S., and Bais, A. F.: The 11-year solar cycle in stratospheric ozone: comparison between Umkehr and SBUV v8 and effects on surface erythemal irradiance, J. Geophys. Res., 111, doi:10.1029/2006JD007760, 2007.

Waters, J.: Microwave limb sounding of Earth's upper atmosphere, Atmos. Res., 23, 391-410, 1989.

White, W. B., Dettinger, M. D., and Cayan, D. R.: Sources of global warming of the upper ocean on decadal period scales, J. Geophys. Res., 108(C8), 3248, doi:10.1029/2002JC001396, 2003.

Williams, J., Austin, J., and Haigh, J.: Model simulations of the impact of the 27-day solar rotation period on the stratosphere, Adv. Space Res., 27, 1933-1942, 2001.

Zerefos, C. S., Tourpali, K., Bojkov, B. R., and Balis, D. S.: Solaractivity-total ozone relationships: observations and model studies with heterogeneous chemistry, J. Geophys., 102, 15611569, 1997.

Zhou, S., Rottman, G. J., and Miller, A. J.: Stratospheric ozone response to short and intermediate-term variations of solar UV flux, J. Geophys. Res., 102, 9003-9011, 1997. 